\title{
AUTOPERCEPÇÃO DA SAÚDE BUCAL POR IDOSOS E A ASSOCIAÇÃO COM INDICADORES CLÍNICOS
}

\section{ORAL HEALTH FOR ELDERLY AND ASSOCIATION WITH CLINICAL INDICATORS}

\author{
Gabriela Furst Vaccarezza* \\ Dayla Padovese Costa* \\ Jéssica Cespedez da Ponta*
}

\section{RESUMO}

Este trabalho foi realizado na Vila dos Idosos, no bairro do Pari, município de São Paulo. Foram aplicados questionários em 91 idosos para avaliar a autopercepção da saúde bucal, seguido de exame clínico para a comparação dos resultados. Os resultados mostram que a autopercepção da saúde bucal tem pouca influência nas situações clínicas. Isso talvez se deva à pouca mais ênfase dada historiacamente a programas educativos e preventivos para a população idosa. Que é de fundamental importância, já que vem aumentado a cada ano sem que haja melhoria para as condições de vida dos idosos.

DESCRITORES: Idoso • Autopercepção • Saúde bucal

\section{ABSTRACT}

Questionnaires were administered to nine one elderly, aged 60-90 yaears of age, who reside in the "Vila dos Idosos" to assess self-perceived oral health, followed by clinical examination. The aim of this study was compare the oral health status with what they think about theirs oral status. The results show that self-perceived oral health suffers littleinfluence on the clinical situation. This may be due to historically low emphasis given to educational and preventative programs for the elderly population. What is of fundamental importance, since this population has increasedeach year.

DESCRIPTORES: Ages.Self • Concept • Oral Health 
VACCAREZZA GF

COSTA DP

PONTA JC

AUTOPERCEPÇÃO

DA SAÚDE BUCAL

POR IDOSOS E

A ASSOCIAÇÃO

COM INDICADORES

CLINICOS

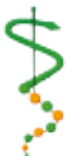

REVISTA DE ODONTOLOGIA DA: UNIVERSIDADE

CIDADE DE SÃO

PAULO

$2010 ; 22(3): 229$

32, SET-DEZ
I N T R O D U ÇÃ O

Segundo a Organização Pan-Americana de Saúde, o envelhecimento é: "um processo sequencial, individual, acumulativo, irreversível, universal, não patológico, de deterioração de um organismo maduro, próprio a todos os membros de uma espécie, de maneira que o tempo o torne menos capaz de fazer frente ao estresse do meio-ambiente e, portanto, aumente sua possibilidade de morte".

O grupo de idosos no Brasil e nos países em desenvolvimento, segundo a (Organização Mundial da Saúde - OMS), é constituído por pessoas a partir de 60 anos. Esse grupo tem aumentado muito nos últimos anos nos países do Terceiro Mundo, devido ao aumento da expectativa de vida, que desde 1900, aumentou de 47 anos para 68 anos, o declínio nas taxas de mortalidade e nas taxas de fecundidade, indicando, assim, a importância de estudos sobre qualidade de vida dos idosos.

O envelhecimento populacional está crescendo, sem que haja melhorias para as condições de vida dessa população. Quanto aos profissionais da área da saúde, é importante que seja abordado assuntos que incluem o estudo das condições bucais desses idosos, assim como sua própria percepção sobre a saúde de sua boca.

Em busca de um diagnóstico mais amplo e preciso, alguns pesquisadores começaram a trabalhar também com medidas subjetivas, visando inserir a percepção do próprio paciente sobre sua condição bucal como um fator relevante à atenção odontológica (Könönen et al. ${ }^{1}$ 1986). Esses dados proporcionam ao profissional subsídios complementares ao exame clínico, permitindo uma visão integral do paciente e, ainda mais, dos modernos conceitos de saúde (Sil$\left.v^{2}, 1999\right)$.

\section{OB J ET I VOS}

Levantar informações sobre as condições e características gerais bucais de um grupo de idosos moradores da Vila dos Idosos, e comparar com a autopercepção da situação de saúde bucal dessa popula- ção específica.

\section{METODOLOG I A}

Foram examinados moradores da Vila dos Idosos com idade maior ou igual a 60 anos, de ambos os sexos.

Para o estudo foram utilizados questionários, e realizado exame clínico na própria Vila dos Idosos. Utilizadou-se um questionário de autoavaliação da saúde bucal, adaptado de Silva e Fernandes ${ }^{3}$ 2001. As respostas foram codificadas através de valores de zero até quatro, sendo o valor zero correspondente à percepção de péssima saúde bucal e o valor quatro excelente.

\section{RESULTADOS}

Foram entrevistados de noventa e um idosos, trinta e nove do sexo masculino e cinquenta e dois do feminino, com idades variando entre 51 e 92 anos. Todos tinham renda de até 3 salários mínimos.

Do total de avaliados, 60,4\% nunca apresentaram dificuldade de pronunciar algumas palavras, sendo que 20,9\% têm este como um acontecimento muito frequente. O paladar, devido a problemas na boca, dentes ou prótese, não se diz alterado para $75,8 \%$ dos entrevistados e $13,2 \%$ sentem alterações muito frequentemente.

Questões como inibição, tensão, dieta insatisfatória, dificuldades para relaxar e realizar trabalhos diários devido a problemas com a boca, dentes ou prótese, nunca ocorreram em 70 a 95\% dos entrevistados.

Foi avaliado se havia dificuldades para se alimentar devido a problemas na boca, dentes ou prótese, e observou-se que mais da metade dos entrevistados apresentavam tais problemas.

As dores na boca ou dentes são muito frequentes em 15,4\% dos idosos entrevistados e nunca ocorreram em 59,3\%.

$\mathrm{Na}$ auto avaliação da saúde bucal, $15,4 \%$ relatam ter uma excelente saúde bucal, enquanto que 40,7\% "boa"; 27,5\% regular; $5,5 \%$ ruim e $11 \%$ péssima. Trinta e quatro por cento relataram ter algum problema com os dentes e $24,2 \%$ negaram qualquer problema gengival.

Dos quatorze idosos que relatam dor muito frequente ao uso da prótese total, 
metade estava satisfeita com a saúde bucal, sendo que cinco deles afirmavam ter uma boa saúde bucal e dois uma excelente. Dos vinte e sete idosos que relatavam dificuldade para comer, onze pontuavam ter uma boa ou excelente saúde bucal.

Após exames clínicos dos idosos, notou-se que todos tinham ao menos perda de um elemento dentário. Os pacientes que possuem dentes naturais são portadores de acúmulo de tártaro e retrações gengivais. Foi feita a análise das próteses totais e removíveis, e estas apresentaram cálculo em regiões posteriores; e três delas apresentavam câmara de vácuo. Foram notadas alterações patológicas como hiperplasia fibrosa inflamatória e alterações fisiológicas como varicorosidades linguais, língua geográfica e fissurada.

\section{DISCUSSÃO E CONCLUSÃO}

Os resultados apresentados são característicos da população estudada, idosos residentes na Vila dos Idosos, não podendo, assim, ser generalizado para todos os idosos do município de São Paulo. A amostra estudada é caracterizada por pouco recurso financeiro, que acaba, de certa forma, interferindo na qualidade de vida.

A autopercepção é importante auxiliar, tanto no diagnóstico quanto no tratamento do paciente, pois indica os sintomas e as expectativas do mesmo diante de sua situação odontológica; porém, deve-se relevar que os indicadores da autoavaliação não devem ser utilizados para diagnosticar doenças e sim como instrumento complementar, identificando as necessidades da população estudada, podendo ser curativas, preventivas e /ou educativas.

Este trabalho relatou uma diferença da situação clínica com a autopercepção do idoso, assim como estudos de Silva e Fernandes $^{3}$ (2001), que concluíram que a pessoa teve visão positiva, mesmo com seus dados não sendo satisfatórios, relevando que o paciente avalia sua condição bucal com critérios diferentes do profissional.

De acordo com Jokovic e Locker $^{4}$ (1997), um dos motivos para essa contradição pode ser explicado pelo fato de muitas das doenças detectadas no exame clínico serem assintomáticas e desconhecidas pelo paciente. Neste estudo, as situações clínicas relatadas pelos pacientes foram as de sintomatologia dolorosa e/ou que comprometiam a estética.

Aproximadamente $70 \%$ dos entrevistados declaram ter uma saúde bucal boa ou ótima; em contrapartida, 34\% relatam ter problemas com os dentes e $75 \%$ algum problema gengival. Os idosos que relatavam dor e/ou alguma dificuldade para se alimentar devido aos dentes, na grande maioria estavam satisfeitos com a sua saúde bucal. Diante desse cenário, observase que, para muitos, a perda dos dentes algum problema relacionado à dentição, com o passar dos anos são acontecimentos naturais, o que não é verdade.

O exame clínico relatou uma ausência de cuidados com as próteses e também de higiene bucal. A avaliação do estado periodontal dos pacientes portadores de dentes naturais provê informações sobre a situação atual e passada. Historicamente a saúde bucal tem sido relegada ao esquecimento quando se discutem as condições de saúde da população idosa. (Colussi e Freitas $^{5}$ 2002). É possível que isso se deva à formação histórica dos profissionais da saúde e da pouca importância que se deu tradicionalmente à saúde bucal.
VACCAREZZA GF

COSTA DP

PONTA JC

AUTOPERCEPÇÃO

DA SAÚdE BUCAL

POR IDOSOS E

A ASSOCIAÇÃO

COM INDICADORES

CLINICOS

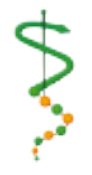

REVISTA DE ODONTOLOGIA DA UNI VERS I DADE Cidade de são PAULO

$2010 ; 22(3): 229-$

32 , SET-DEZ 
AUTOPERCEPÇÃO

DA SAÚDE BUCAL POR IDOSOS E

A ASSOCIAÇÃO COM INDICADORES CLINICOS

1. Könönen M, Lipasti J, Murtomaa H. Comparison of dental information obtained from self - examination and clinical examination Community Dent Oral Epidemiol 1986 Oct;14(5):258-60

2. Silva SRC. Autopercepção das condições bucais em pessoas com 60 anos e mais de idade. São Paulo. Tese [Doutorado] Faculdade de Saúde Pública USP, 1999.

3. Silva SRC ; Fernandes RC. Autopercepção das condições de saúde bucal por idosos Revista Saúde Pública 2001 ago;35(4):349-55

4. Jokovic A, Locker D. Dissatisfaction with oral health status in an older adult population. J Public Health Dent 1997;57(1):40-7.

5. Colussi CF, Freitas SFT. Aspectos epidemiológicos da saúde bucal do idoso no Brasil Cad Saúde Pública 2002 set.-out;18(5):1313-20

Recebido em: 16/08/2010

Aceito em: 18/09/2010 